\title{
Pilocarpine: The Dosage Dogma
}

\author{
George L Spaeth, Suzanne G Li, Parul Ichhpujani, Germana M Donaire
}

Department of Ophthalmology, Jefferson Medical College, William and Anna Goldberg Glaucoma Service

Wills Eye Institute Philadelphia, PA, USA

Pilocarpine, a direct acting parasympathomimetic, is the most extensively studied miotic. The effect of pilocarpine on intraocular pressure, when administered as a single drop, has been investigated in the past. ${ }^{1-4}$ However, Harris and Galin reported that single dose experiments cannot be considered valid indicators of the expected clinical effects of pilocarpine when the drug is given repeatedly. ${ }^{5}$ In this investigation, pilocarpine was given in repeated doses, to evaluate the effects of different concentrations of pilocarpine hydrochloride on intraocular pressure (IOP). This study evaluated the hypotensive effects of clinically used strengths of pilocarpine and various clinical characteristics which may serve as indicators of responsiveness of patients to pilocarpine.

This study was approved by the Wills Eye Institute Institutional Review Board (IRB\#08-914E). Informed consent was obtained prior to the initial screening evaluation. This was a prospective analysis of patients aged 18 years or older with primary open angle glaucoma (POAG) or open angle glaucoma suspects. Patients were selected from Glaucoma Service of Wills Eye Institute. Patients were either naive to glaucoma therapy or administering topical medications other than long acting miotics. Patients were excluded from the study if they had coexisting ocular pathology, recent ocular surgery, or ocular inflammation or ocular infection within 3 months prior to the screening visit, previously recorded allergy to pilocarpine, pregnant women or nursing mothers.

The study included 22 patients (44 eyes). The demographic data is elucidated in Table 1 . All glaucoma medications were stopped 30 days prior to the study. At the start of the study the following parameters were checked: visual acuity, color of the iris (blue, brown or hazel), size of the pupil, IOP measurement by Goldmann applanation tonometer $\left(\mathrm{P}_{0}\right)$, gonioscopy for configuration of the angle, slit-lamp biomicroscopy using a +66D lens for cup-to-disk ratio, depth of the cup and degree of pallor of the disk and visual field by Humphrey Field Analyzer (Carl Zeiss Meditec, Inc.). A 4 minutes pressure tracing was obtained with a needle recorder attached to the indentation tonometer while it was gently applied to the cornea. Its position on the cornea was maintained until a smooth tracing for 4 minutes was obtained. The $\mathrm{P}_{0}$ and the change in scale reading during the 4 minutes were then used to obtain the coefficient of outflow facility (C) from tonographic Tables. ${ }^{6}$
Table1: Patient demographics

\begin{tabular}{lr}
\hline Patients enrolled & 22 \\
Age range (in years) & $45-75$ \\
Race & \\
- African-Americans & 18 \\
- Euro-Americans & 4 \\
Diagnosis & \\
- POAG & 31 \\
- POAG suspects & 13 \\
\hline
\end{tabular}

Each concentration of pilocarpine hydrochloride was used 4 times daily for two days (12 noon, 4 pm, 10 pm and 8 am). New drops of different concentration were given to patients at each follow-up visit (Table 2). Patients were examined between 9 am and $11 \mathrm{am}$. Re-examination of IOP, visual acuity and pupil size were done at each visit. Sixteen patients were instructed to use pilocarpine in a sequence of decreasing concentration (12 patients: $8 \%, 2 \%$ and $0.5 \%$ pilocarpine in that order, and 4 patients: $8 \%, 4 \%, 2 \%$ and $0.5 \%$ pilocarpine), while six patients were told to use the medication in the sequence of increasing concentration $(0.5 \%, 2 \%, 4 \%$ and $8 \%$ in that order).

Patients were divided into two groups based on responsiveness of their IOP to pilocarpine: a decrease of $3 \mathrm{~mm}$ Hg or more was considered "responsive", while a fall of less

Table 2: Study protocol

\begin{tabular}{llr}
\hline Visit & Regimen & Duration \\
\hline Screening & Washout of medications, if necessary & 30 days \\
1; Baseline & Detailed work-up & D0 \\
2 & $\begin{array}{l}\text { Pilocarpine 8\% (or 0.5\%) OU } \\
\text { qds@12pm,4pm,10pm,8am }\end{array}$ & D1-D2 \\
3 & $\begin{array}{l}\text { Pilocarpine 4\% (or 2\%) OU } \\
\text { qds@12pm,4pm,10pm,8am }\end{array}$ & D3-D4 \\
4 & $\begin{array}{l}\text { Pilocarpine 2\% (or 4\%) OU } \\
\text { qds@12pm,4pm,10pm,8am }\end{array}$ & D5-D6 \\
5 & Pilocarpine 0.5\% (or 8\%) OU & D7-D8 \\
6; Termination & Nds@12pm,4pm,10pm,8am & D9 \\
\hline
\end{tabular}

than $3 \mathrm{~mm}$ Hg was "unresponsive”. Twenty-one eyes (47.7\%) were responsive and 15 eyes (34.1\%) were unresponsive. The four patients (8 eyes) responsive to one concentration of 
pilocarpine but not to others were not included in the analysis of results.

At the end of the study the amount of change in IOP was compared with various parameters: baseline IOP, duration of disease, coefficient of aqueous outflow, amount of optic atrophy, and degree of visual field defect. These characteristics were compared to study their influence on responsiveness to pilocarpine.

The results were analyzed by the Student's " $t$ " test for paired data. The level of significance of 0.01 was chosen to reflect a statistically meaningful difference.

Table 3 summarizes the effect of various concentrations of pilocarpine on the IOP. The specific sequence in which different concentrations of pilocarpine were administered did not alter the hypotensive effect. Treatment with pilocarpine in all concentrations greater than $0.5 \%$ had a highly significant IOP lowering effect when compared with no treatment $(\mathrm{p}<0.01)$ (Table 4).

Table 5 shows the dose-response to various concentrations of pilocarpine of the responsive and the unresponsive groups.

Table 3: The effect of pilocarpine drops given four times daily for two days $(n=44)$

\begin{tabular}{lc}
\hline Concentration of pilocarpine & Mean $\mathrm{IOP} \pm S D(\mathrm{~mm} \mathrm{Hg})$ \\
\hline No treatment & $23.9 \pm 5.82$ \\
$0.5 \%$ & $20.0 \pm 5.12$ \\
$2 \%$ & $18.5 \pm 3.53$ \\
$4 \%$ & $17.5 \pm 4.33$ \\
$8 \%$ & $17.0 \pm 3.75$ \\
\hline
\end{tabular}

Table 4: Comparison of hypotensive effect of various concentrations of pilocarpine

\begin{tabular}{|c|c|}
\hline Concentration of pilocarpine & Level of significance \\
\hline \multicolumn{2}{|l|}{ No $\mathrm{Rx}^{*} \rightarrow 0.5 \%$} \\
\hline No $\mathrm{Rx}^{*} \rightarrow 2 \%$ & 0.01 \\
\hline No $\mathrm{Rx} \rightarrow 4 \%$ & 0.0 \\
\hline No $\mathrm{Rx}^{*} \rightarrow 8 \%$ & 0.0 \\
\hline $0.5 \% \rightarrow 2 \%$ & 0.1 \\
\hline $0.5 \% \rightarrow 8 \%$ & 0.05 \\
\hline $2 \% \rightarrow 4 \%$ & 0.3 \\
\hline $2 \% \rightarrow 8 \%$ & 0.15 \\
\hline $4 \% \rightarrow 8 \%$ & 0.45 \\
\hline
\end{tabular}

* Without previous treatment
Table 5: Hypotensive effect of pilocarpine, given four times daily in responsive and unresponsive groups

\begin{tabular}{lcc}
\hline $\begin{array}{l}\text { Concentration of } \\
\text { pilocarpine }\end{array}$ & $\begin{array}{c}\text { Mean IOP } \pm \text { SD } \\
(\mathrm{mm} \mathrm{Hg}) \text { responsive } \\
\text { group }(n=21)\end{array}$ & $\begin{array}{c}\text { Mean IOP } \pm \text { SD } \\
(\mathrm{mm} \mathrm{Hg}) \text { unresponsive } \\
\text { group }(n=15)\end{array}$ \\
\hline No treatment & $26.9 \pm 5.64$ & $18.9 \pm 1.31$ \\
$0.5 \%$ & $20.1 \pm 5.69$ & $18.8 \pm 2.48$ \\
$2 \%$ & $17.4 \pm 3.05$ & $18.3 \pm 2.36$ \\
$8 \%$ & $16.6 \pm 3.48$ & $17.5 \pm 3.42$ \\
\hline
\end{tabular}

Pilocarpine concentrations up to 8\% did not cause a significant reduction of IOP in this group (Table 6).

An effort was made to identify pilocarpine-responsive eyes by analyzing various characteristics: IOP, duration of the disease, coefficient of aqueous outflow, amount of optic atrophy and degree of visual field defect. Tables 7 and 8 summarize the decrease in IOP for the various groups when treated with different concentrations of pilocarpine. Eyes with pretreatment IOP greater than $22 \mathrm{~mm} \mathrm{Hg}$ showed a greater responsiveness to pilocarpine ( $0.5 \%$ or greater) than untreated eyes, whereas eyes with a pretreatment IOP below $21 \mathrm{~mm} \mathrm{Hg}$ did not show this response.

Table 6: Comparison of hypotensive effect of various concentrations of pilocarpine in responsive and unresponsive groups

\begin{tabular}{|c|c|c|}
\hline $\begin{array}{l}\text { Concentration of } \\
\text { pilocarpine }\end{array}$ & $\begin{array}{c}P \\
\text { (Responsive group) }\end{array}$ & $\begin{array}{c}P \\
\text { (Unresponsive group) }\end{array}$ \\
\hline No $\mathrm{Rx}^{*} \rightarrow 0.5 \%$ & - & $>0.01$ \\
\hline No $\mathrm{Rx}^{*} \rightarrow 2 \%$ & 0.01 & $>0.01$ \\
\hline No $\mathrm{Rx}^{*} \rightarrow 4 \%$ & 0.01 & 一 \\
\hline No $\mathrm{Rx}^{*} \rightarrow 8 \%$ & 0.01 & $>0.01$ \\
\hline $0.5 \% \rightarrow 2 \%$ & 0.05 & $>0.01$ \\
\hline $0.5 \% \rightarrow 8 \%$ & 0.01 & $>0.01$ \\
\hline $2 \% \rightarrow 8 \%$ & 0.25 & $>0.01$ \\
\hline
\end{tabular}

* Without previous treatment

\section{DISCUSSION}

This multiple-dose study showed that a statistically significant hypotensive effect is obtained with pilocarpine hydrochloride 0.5 to $8 \%$, 4 times daily, in POAG suspects and those with POAG. This is in agreement with previous studies. ${ }^{7,8}$ Harris and Galin reported that $1 \%$ pilocarpine has a near-maximal pressurelowering effect in subjects with blue iris, while a higher concentration is needed to obtain a similar effect in those with dark brown irides, ${ }^{9}$ because our patient population consisted 


\begin{tabular}{|c|c|c|c|c|c|c|}
\hline \multirow[t]{2}{*}{ Parameters } & \multicolumn{2}{|c|}{$\begin{array}{l}\text { No } R x^{*} \rightarrow 0.5 \% \\
\text { Difference }\end{array}$} & \multicolumn{2}{|c|}{$\begin{array}{c}\text { No } R x^{*} \rightarrow 2 \% \\
\text { Difference }\end{array}$} & \multicolumn{2}{|c|}{$\begin{array}{c}\text { No } R^{*} \rightarrow 8 \% \\
\text { Difference }\end{array}$} \\
\hline & $\mathrm{mm} \mathrm{Hg}$ & $\%$ & $m m H g$ & $\%$ & $\mathrm{~mm} \mathrm{Hg}$ & $\%$ \\
\hline Disease present less than 5 years & 3.0 & 13.3 & 4.7 & 20.4 & 5.8 & 25.6 \\
\hline Disease present more than 5 years & 6.1 & 22.7 & 7.3 & 27.3 & 8.4 & 31.3 \\
\hline Coefficient aqueous outflow 0.11 & 3.6 & 13.7 & 6.2 & 23.8 & 8.7 & 33.6 \\
\hline Coefficient aqueous outflow 0.19 & 5.2 & 21.5 & 7.6 & 31.7 & 7.7 & 32.1 \\
\hline No optic nerve pallor & 2.7 & 11.8 & 3.3 & 14.8 & 5.8 & 25.6 \\
\hline Moderate to advanced optic nerve pallor & 5.9 & 20.7 & 10.9 & 38.3 & 10.3 & 36.3 \\
\hline Normal visual field & 3.4 & 15.0 & 4.0 & 17.7 & 5.7 & 25.2 \\
\hline Moderate to advanced visual field loss & 2.6 & 10.6 & 6.0 & 24.8 & 6.1 & 25.3 \\
\hline
\end{tabular}

* Without previous treatment

of 18 African-American and only 4 Euro-Americans, no conclusive comments can be made in this regard.

One single-dose study using pilocarpine 1 to $10 \%$ failed to demonstrate an increasing effect on IOP with increasing concentration. ${ }^{10}$ Multiple-dose strategy used in our study, is similar to the manner in which pilocarpine is used in clinical practice, and it showed that additional hypotensive effect is seen with increased concentrations of pilocarpine (0.5 to 8\%).

In the present study it was evident that there are two groups, those responsive to pilocarpine and those much less responsive. Pretreatment IOP was a good indicator of responsiveness to pilocarpine. Krill and Newell have already reported that the hypotensive effect of pilocarpine is proportional to the predrug pressure level. ${ }^{11}$ Eyes with pretreatment IOP greater than $22 \mathrm{~mm} \mathrm{Hg}$ in our study showed a typical dose-response to pilocarpine while pretreatment IOP below $21 \mathrm{~mm} \mathrm{Hg}$ did not show this response (Table 8).

Table 8: Responsiveness of IOP to pilocarpine

\begin{tabular}{lc}
\hline & $P$ less than \\
\hline Visual field loss $v s$ normal field & 0.25 \\
C. $\downarrow 0.11$ vs C. $\uparrow$ 0.19 & $0.01 \dagger$ \\
Disease 5 years $v s$ less than 5 years & 0.3 \\
IOP (No Rx $\left.{ }^{*}\right)>25$ mm Hg vs IOP (No Rx $\left.{ }^{*}\right)<25$ mm Hg & $0.01 \dagger$ \\
Optic atrophy vs no optic atrophy & 0.20 \\
\hline
\end{tabular}

$\mathrm{C}=$ Facility of outflow;* Without previous treatment; $\dagger$ With statistical significance
The coefficient of aqueous outflow was also related to hypotensive effect. Eyes with a coefficient of aqueous outflow 0.19 or greater responded better to pilocarpine than the eyes with a coefficient of aqueous outflow of 0.10 or less (Table 8). This was particularly evident with weaker strengths, especially with pilocarpine $2 \%(\mathrm{p}<0.01)$, and was less appreciable with higher concentrations. It is thought that pilocarpine lowers IOP by increasing facility of outflow by mechanical alteration of the trabecular meshwork. ${ }^{7,12}$ Elastic-like fibers continuous with elastic tendons of the ciliary muscle run perpendicularly through the meshwork and attach to the area adjacent to the endothelial lining of Schlemm's canal. ${ }^{7,12-14}$ Hence it is logical, in view of the mechanism of action of pilocarpine, that eyes with a greater coefficient of outflow would respond better to pilocarpine.

Eyes with moderate to advanced optic atrophy also showed a slightly greater hypotensive response to pilocarpine than eyes with no optic atrophy, but the difference was not statistically significant $(p<0.20)$. A similar result was seen when eyes with moderate to advanced field defect were compared with eyes with apparently normal visual fields $(\mathrm{p}<0.25)$. However, even such a slight correlation may be misleading. Eyes with optic atrophy and visual field loss also had higher IOP, and it is likely that the pressure was a more valid indicator of responsiveness.

Patients with disease duration longer than five years had higher IOP than those whose disease was of shorter duration. The responsiveness of the groups, however, was not significantly different (Table 8).

Of the four Euro-Americans in the study, two demonstrated a marked decrease of IOP in response to pilocarpine, one an 
intermediate change and one with negligible change in IOP. The first three cases had blue iris and the last had brown iris. This finding is in agreement with previous studies that have described a greater hypotensive effect of pilocarpine in individuals with blue irides as compared to brown irides. ${ }^{9}$

The most important finding in this study was the observation that about one-third of the patient had no significant response to pilocarpine. In 15 of the 41 eyes (nonresponsive group), increasing the concentration of pilocarpine had little effect. In contrast, in those eyes that were responsive to the IOP lowering effect of pilocarpine, increasing the concentration of the drug from 0.5 to $2 \%$ was associated with a better than $75 \%$ chance of obtaining a significantly lower tension. Moreover, an increase of sixteen-fold resulted in a 99\% chance of obtaining additional hypotensive effect (Table 6).

These calculations regarding responsiveness refer to populations, not individuals. For any given person there is as yet no definite valid indicator of responsiveness to pilocarpine. Furthermore, even within populations the indications of responsiveness are not absolute. Therefore, it is probably appropriate to use pilocarpine in the form of a therapeutic trial so that its actual effectiveness in the individual under consideration can best be determined.

To summarize, when pilocarpine is indicated and adequate pressure-lowering is not achieved with a concentration of $1 \%$ or $2 \%$ used 4 times daily, the likelihood is small that there will be a clinically significant further decrease in IOP if stronger concentrations such as $4 \%$ or $8 \%$ are employed. The stronger concentrations carry with them more side effects, such as accommodative spasm, miosis and possibly retinal detachment. ${ }^{14}$ The amount of concern for these side effects must be considered in deciding upon an appropriate therapeutic program.

\section{REFERENCES}

1. Kronfeld PC. Dose-effect relationships as an aid in the evaluation of ocular hypotensive drugs. Invest Ophthalmol 1964;3:258-65.

2. Drance SM, Benstead M, Schulzer M. Pilocarpine and intraocular pressure, Duration of effectiveness of $4 \%$ and $8 \%$ pilocarpine instillation. Arch Ophthalmol 1974;91:104-06.

3. Drance SM, Nash PA. The dose response of human intraocular pressure to Pilocarpine. Can J Ophthalmol 1951;6:9-13.

4. Fenton R, Schwartz B. The effect of $2 \%$ pilocarpine on the normal and glaucomatous eyes.I.The time response of pressure. Invest Ophthalmol 1963;2:289.
5. Harris LS, Galin MA. Dose responsive analysis of pilocarpine induced ocular hypotension. Arch Ophthalmol 1970;84:60509.

6. Grant WM, Schuman JS. Tonometry and tonography. In: Epstein DL, Allingham RR, Schuman JS (Eds). Chandler and Grant's Glaucoma. (4th ed.) Baltimore, Md; Williams and Wilkins;1997.

7. Kaufman PL, Gabelt BT. Direct, indirect, and dual-action parasympathetic drugs. In: Zimmerman TJ, Sharir M, Fechtner RD (Eds). Textbook of Ocular Pharmacology. Lippincott-Raven: Philadelphia 1997;221-38.

8. Brinchmann-Hansen O, Anmarkrud N. Pilocarpine medication in open-angle glaucoma. A study using pilocarpine eyedrops and an ocular therapeutic system. Acta Ophthalmol (Copenh) 1979;57(1):55-62.

9. Harris LS, Galin MA. Effect of ocular pigmentation on hypotensive response to pilocarpine. Am J Ophthalmol 1971;72(5):923-25.

10. Harris LS, Galin MA. Dose-responsive analysis of pilocarpineinduced ocular hypotension. Arch Ophthalmol 1970;84(1):60509.

11. Krill AE, Newell FW. Effects of Pilocarpine on Ocular Tension Dynamics. Am J Ophthalmol 1964;57:34-41.

12. Toris CB, Zhan GL, Zhao J, et al. Potential mechanism for the additivity of pilocarpine and latanoprost. Am J Ophthalmol 2001;131(6):722-28.

13. Kaufman PL, Barany EH. Loss of acute pilocarpine effect on out-flow facility following surgical disinsertion and retrodisplacement of the ciliary muscle from the scleral spur in the cynomolgus monkey. Invest Ophthalmol 1976;15:793-807.

14. Brubaker RF. Targeting outflow facility in glaucoma management. Surv Ophthalmol 2003;48 (Suppl 1):S17-20.

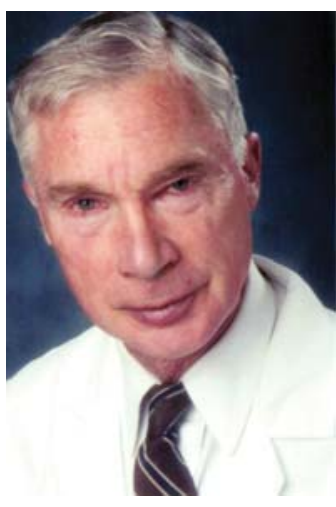

George L Spaeth (gspaeth@ willseye.org) 